\title{
Tuberculose endobrônquica em lactente: a importância do diagnóstico precoce
}

\author{
Endobronchial tuberculosis in infants: the importance of early \\ diagnosis
}

\author{
Selma Maria de Azevedo Sias', Carmem Lucia de Castro', Laura Cristina de Souza', Caio Vasconcellos', Ana \\ Letícia Pinto $^{1}$ e Berenice Gonçalves ${ }^{1}$
}

'Universidade Federal Fluminense, Niterói - RJ

\section{Palavras-chave:}

Tuberculose; Brônquios; Diagnóstico; Broncoscopia; Líquido da lavagem broncoalveolar; Lactente.

\section{Resumo}

Introdução: a tuberculose endobrônquica é a complicação mais frequente de tuberculose pulmonar em crianças. Tem diagnóstico difícil, exigindo alto índice de suspeita. As características clínicas e radiológicas são inespecíficas, sendo confundida com pneumonia, asma, corpo estranho e tumor. O tratamento é o mesmo da tuberculose pulmonar, sendo a adição de corticosteroide ainda controversa. Objetivo: relatar um caso de tuberculose endobrônquica em um lactente, com ótima resposta ao tratamento específico associado a corticosteroide. Descrição do caso: menino, 4 meses, internado por pneumonia, sem melhora após esquemas antimicrobianos. Padrasto tratando tuberculose pulmonar. Mãe, usuária de drogas, com tuberculose pleural não tratada, tendo evoluído a óbito na época da internação do lactente. Ele foi transferido para um hospital universitário. Na admissão havia discordância clinicorradiológica, taquipneia, dispneia, sibilos difusos e estertores. Radiografia de tórax: mesma imagem do hospital de origem. Tomografia de alta resolução de tórax: atelectasia do lobo superior direito e linfonodomegalias mediastinais. Hemograma: anemia e leucocitose com desvio à esquerda. Proteína C-reativa elevada. Broncoscopia: compressão extrínseca e caseum no brônquio do lóbulo superior direito. Cultura do lavado broncoalveolar isolou Mycobacterium tuberculosis. Discussão: a história de pneumonia sem resposta ao tratamento associado ao contato familiar com tuberculose e a discordância clinicorradiológica direcionam para o diagnóstico de tuberculose pulmonar, corroborado pelo sistema de pontuação do Ministério da Saúde. A compressão das vias aéreas é suspeitada nos casos de tuberculose que apresentam tosse, sibilos e pneumonia não responsiva, linfonodomegalia mediastinal, hiperinsuflação e atelectasia pulmonar. Os sinais clínicos, radiológicos, tomográficos e broncoscópicos de obstrução brônquica sugeriram tuberculose endobrônquica. Corticosteroide foi associado ao esquema terapêutico antituberculose, obtendo-se resolução completa.

\section{Keywords:}

Tuberculosis; Bronchi; Diagnosis; Bronchoscopy; Bronchoalveolar lavage fluid; Infant.

\begin{abstract}
Introduction: endobronchial tuberculosis is the most frequent complication of pulmonary tuberculosis in children. The diagnosis is difficult and it requires a high level of suspicion. The clinical and radiological features are nonspecific, and it is confused with pneumonia, asthma, foreign body and tumor. The treatment is the same as pulmonary tuberculosis, but the include of corticosteroid is still controversial. Objective: to report endobronchial tuberculosis in an infant, with an excellent response to the specific treatment associated to corticosteroid. Case description: boy, 4 months, hospitalized for pneumonia, without improvement after antimicrobial schedules. His stepfather was treating pulmonary tuberculosis. His mother, drug user, with untreated pleural tuberculosis, evolved to death at the time of the infant's hospitalization. He was transferred to university hospital. At admission there were clinical-radiological disagreement, tachypneic, dyspneic, diffuse wheezing and rales. Chest X-Ray: same image of the hospital of origin. Chest HRCT: LSD atelectasis and mediastinal lymphadenopathy. Hemogram: anemia and leukocytosis with predominance of polymorphonuclear. High PCR. Bronchoscopy: extrinsic compression and caseum in BLSD. Culture of bronchoalveolar lavage with Mycobacterium tuberculosis. Discussion: the history of pneumonia non-responsive to treatment associated to family contact with tuberculosis and clinical radiological discordance lead to the diagnosis of pulmonary tuberculosis, corroborated by the MS scoring system. Airway compression have been suspected in cases of coughing, wheezing, pneumonia not responsive, mediastinal lymphadenopathy, hyperinflation and pulmonary atelectasis. Clinical, radiological, tomographic and bronchoscopic signs of bronchial obstruction suggested endobronchial tuberculosis. Corticosteroid was associated to the therapeutic antituberculosis getting complete resolution.
\end{abstract}




\section{INTRODUÇÃO}

No Brasil estima-se que $15 \%$ dos casos de tuberculose (TB) diagnosticados ocorram em menores de 15 anos, sendo que os menores de 2 anos têm o dobro das taxas de adoecimento, com predomínio da forma pulmonar. Entretanto, a dificuldade em coletar escarro na criança e a escassez de bacilos dificultam o diagnóstico na população pediátrica, provavelmente subestimando o diagnóstico da TB pulmonar. ${ }^{1}$ A TB endobrônquica (TBEB) é considerada a complicação mais frequente de TB pulmonar em crianças, sendo encontrada entre 41 a $63 \%$ dos casos. ${ }^{2,3} \mathrm{O}$ diagnóstico desta forma de TB é difícil e exige alto índice de suspeita, pois as características clínicas são inespecíficas, frequentemente confundidas com pneumonia, asma, corpo estranho, tumor, e as lesões podem não ser evidentes na radiografia de tórax, retardando o diagnóstico e o tratamento. ${ }^{4} \mathrm{Na}$ TBEB o envolvimento das vias aéreas também pode ser sinalizado quando durante o tratamento da TB pulmonar não há melhora ou ocorre piora clínica e radiológica. Assim, torna-se importante reconhecer e diferenciar os casos de TBEB de casos de TB pulmonar considerados como falha ou resistentes ao tratamento. ${ }^{2,5}$ Além disso, a TBEB pode evoluir com sequelas como bronquiectasia e estenose brônquica, aumentando a morbidade da doença. O tratamento é o mesmo preconizado para TB pulmonar. A adição de corticosteroide ao esquema de drogas antituberculose no tratamento da TBEB ainda é controverso. ${ }^{4,5} \mathrm{O}$ objetivo é relatar um caso de TBEB em um lactente que após o diagnóstico apresentou ótima resposta ao tratamento específico associado a corticosteroide.

\section{DESCRIÇÃO DO CASO}

D. O. S., 4 meses, masculino, branco. Apresentou tosse produtiva por duas semanas, evoluindo com febre e dispneia, sendo diagnosticada pneumonia em serviço de emergência e indicada internação. Foi medicado com broncodilatador e antibióticos (ampicilina, amoxicilina associada a clavulanato e cefepime), sem melhora clínica e radiológica, motivo de sua transferência para o Hospital Universitário Antônio Pedro (HUAP) no oitavo dia do terceiro esquema antimicrobiano. Prova tuberculínica (PPD) não reatora - realizada no hospital onde esteve internado. O padrasto estava em tratamento ambulatorial de TB pulmonar há três meses. A mãe, usuária de drogas, recusou internação para tratar TB pleural, evoluindo a óbito quando o lactente foi internado.

Na admissão do HUAP o menor encontrava-se em bom estado geral, afebril, palidez cutaneomucosa leve, taquipneico, com sibilos difusos e estertoração subcrepitante em hemitórax direito. A radiografia de tórax mostrava consolidação com componente atelectásico no lobo superior direito semelhante à encontrada no hospital de origem e na tomografia de tórax, evidências de atelectasia do lobo superior direito devido à compressão brônquica, linfonodomegalias paratraqueais, hilar direita, pré-carinais e infracarinais (Figura 1).

O sistema de pontuação do Ministério da Saúde (MS) indica diagnóstico muito provável (40 pontos). Hematimetria $=3,96 \times 10 / \mathrm{mm}^{3}$, hemoglobina $=10,6$ $\mathrm{g} / \mathrm{dl}$, hematócrito $=32,3 \%$, leucócitos globais $=13,6 \times$ $10^{3} / \mathrm{mm}^{3}$ (diferencial em porcentagem: basófilo $=0$, eosinófilo $=4$, bastões $=14$, segmentados $=21$, linfócitos $=59$, monócitos $=4)$. Proteína c-reativa $(\mathrm{PCR})=17,25$ $\mathrm{mg} / \mathrm{dl}$, plaquetas $=385 \times 10^{3} / \mathrm{mm}^{3}$. Broncoscopia flexível identificou carina alargada, importante redução de calibre do brônquio do lobo superior direito por compressão extrínseca, dificultando a visualização dos segmentos, e protrusão na sua parede medial com caseum (Figura 2).

O lavado broncoalveolar (LBA) apresentou pesquisa de bacilos álcool-ácido resistentes (BAAR) negativa, mas a cultura isolou Mycobacterium tuberculosis, sensível à isoniazida e rifampicina. Em uma segunda amostra do lavado gástrico houve BAAR negativo, mas cultura também positiva. Foi iniciado tratamento específico com esquema tríplice (isoniazida, rifampicina e pirazinamida) associado a prednisona, havendo melhora evolutiva e alta hospitalar após 16 dias, com encaminhamento para a unidade básica de saúde. A radiografia de tórax realizada após a finalização do esquema básico de tratamento foi normal.

\section{DISCUSSÃO}

O comprometimento das vias aéreas na criança com TB pulmonar é comum, variando entre 41 a $63 \%$ dos casos, podendo ocorrer no início da doença ou durante o seu tratamento. ${ }^{2,3}$ Os principais locais de acometimento da via aérea nos casos de TBEB são o brônquio principal direito e a traqueia, embora qualquer área da árvore traqueobrônquica possa ser afetada. ${ }^{3}$

Na faixa etária pediátrica, a obstrução das vias aéreas devido a compressão ou estreitamento ocorre com maior facilidade devido às vias aéreas mais compressíveis pela imaturidade do arcabouço cartilaginoso traqueobrônquico e o menor diâmetro das vias aéreas. ${ }^{6,7}$

Deve-se reconhecer e diferenciar os casos de TB pulmonar com envolvimento das vias aéreas dos casos com falha de tratamento ou resistência a drogas, visto que o diagnóstico precoce e o tratamento adequado são cruciais para evitar complicações. ${ }^{2,8}$ 
Figura 1 - Radiografias de tórax: A) condensação no lobo superior direito com componente atelectásico, redução de calibre do brônquio principal direito; B) resolução após tratamento com esquema tríplice e prednisona; C) tomografia de alta resolução de tórax (16/10/2013) mostra na janela de mediastino com compressão brônquica, linfonodomegalias paratraqueais, hilar direita, pré-carinais e infracarinais
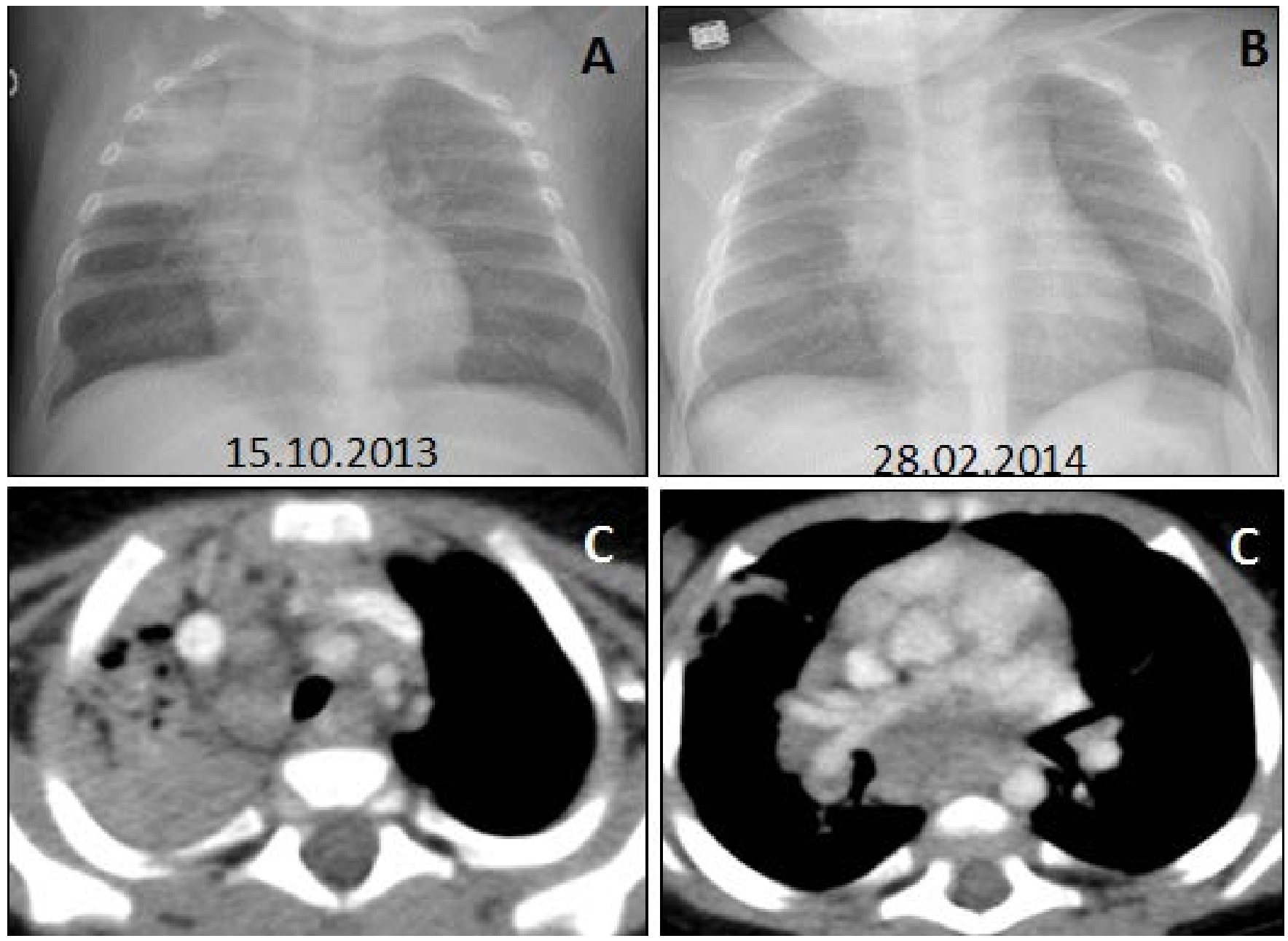

Fonte: Arquivo pessoal $(2013,2014)$

Figura 2 - Broncoscopia flexível mostra obstrução da luz do brônquio do lóbulo superior direito com protrusão da parede e caseum

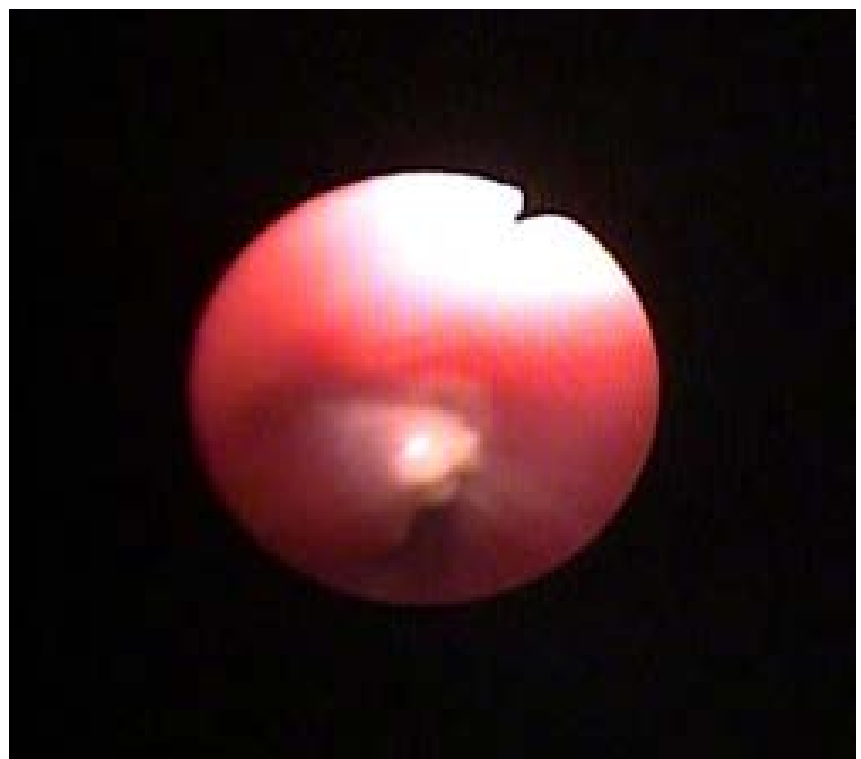

A TBEB tem apresentação clínica variável. Pode se manifestar: de forma aguda - simulando pneumonia refratária, atelectasia, asma e aspiração de corpo estranho devido ao comprometimento brônquico com obstrução; de forma insidiosa - simulando pneumonia de evolução arrastada e câncer de pulmão; ou tardia - manifestando-se tempos depois do tratamento da TB, com estenose traqueobrônquica. ${ }^{7,9,10}$ A compressão das vias aéreas é suspeitada nos casos de tosse persistente, sibilos unilaterais, pneumonia expansiva, pneumonia não responsiva ao tratamento convencional, linfonodomegalia, hiperinsuflação e atelectasia pulmonar. ${ }^{2,9}$ Nosso lactente apresentava sinais clínicos de obstrução brônquica no exame físico e foi internado com diagnóstico de pneumonia bacteriana, sendo submetido a três esquemas antimicrobianos, porém sem resposta clínica e radiológica. O fato é que não se tratava de pneumonia refratária ao tratamento, mas de uma complicação

Fonte: Arquivo pessoal (2014). 
devido ao envolvimento brônquico pela $\mathrm{TB}$, causando obstrução brônquica e atelectasia do lobo superior direito. Na prática, a aplicação do sistema de pontuação do MS para diagnóstico de TB pulmonar em crianças e em adolescentes negativos à baciloscopia ${ }^{1}$ já permitiria o início do tratamento, visto que totaliza 40 pontos. Porém, os indícios de envolvimento brônquico como a redução volumétrica pulmonar sugerindo atelectasia, presentes na radiografia de tórax, corroborada pela tomografia computadorizada e pela broncoscopia, sugere comprometimento endobrônquico grave e, neste caso, seria conveniente associar corticosteroide ao esquema tríplice.

A principal característica da TBEB na criança é a presença de linfonodomegalia mediastinal. Lucas e colaboradores ${ }^{6}$ estudaram retrospectivamente 98 tomografias de tórax de crianças com TB pulmonar comprovada por cultura. Os autores observaram que a maioria (99\%) apresentava mais de um sítio comprometido com enfartamento ganglionar, sendo os mais comuns o subcarinal, paratraqueal e hilar direitos, e como complicações mais frequentes: consolidação $(44,7 \%)$, colapso pulmonar $(16,4 \%)$ e aprisionamento aéreo $(15,6 \%)$. O caso aqui relatado apresentou comportamento semelhante, com mais de um sítio ganglionar (paratraqueal bilateral, hilar direito, pré e infracarinal), além de colapso do lobo superior direito.

Sabe-se que na patogênese da TBEB, os linfonodos adjacentes às grandes vias aéreas aumentam de volume, causando obstrução extraluminal ou intraluminal e algumas vezes infiltram a parede das vias aéreas. A obstrução extraluminal deve-se à compressão dos linfonodos aumentados com edema inflamatório associado, enquanto que a intraluminal resulta da presença de tumoração com pólipos ou tecido granulomatoso, consequente à infiltração da parede brônquica que pode evoluir com erosão e eliminação de caseum para o interior da luz brônquica. ${ }^{3} \mathrm{O}$ caso relatado apresentava obstrução intraluminal com presença de caseum identificado pela broncoscopia.

Na broncoscopia, o acometimento brônquico do paciente com TBEB pode ser classificado em sete tipos diferentes: caseum ativo, edematoso-hiperêmico, fibroestenótico, tumoral, granular, ulcerativo e bronquite não específica, podendo evoluir de uma forma para outra. ${ }^{4,8}$ Inclusive, a forma tumoral, considerada a mais complicada, deve ser acompanhada a curto e a longo prazo devido à evolução das lesões e ao surgimento de estenose brônquica numa fase mais tardia. ${ }^{10}$ Nossa criança apresentava compressão extrínseca por linfonodomegalia e caseum. Como a evolução clínica foi satisfatória, com normalização radiológica após tratamento específico associado a corticosteroide, optou-se por não realizar broncoscopia de controle pela natureza invasiva do exame, além de submeter o lactente a anestesia geral.

De Blic e cols. ${ }^{11}$ realizaram broncoscopia flexível em 54 crianças com TB pulmonar, com idades entre 4 meses e 14 anos, encontrando compressão das vias aéreas em 20 casos, tecido de granulação em 10 e obstrução por caseum em 4 . Cakir e cols. ${ }^{2}$ estudaram 167 crianças entre 2 meses e 16 anos de idade, com TB pulmonar submetidas à broncoscopia e encontraram envolvimento de vias aéreas em $55 \%$ delas. Observaram associação significativa entre a TBEB e a resistência ao tratamento e associação entre a baixa idade e a presença de linfonodomegalias paratraqueais, porém sem significância estatística. As lesões mais frequentemente encontradas foram: obstrução endoluminal por massa polipoide (42\%), compressão extrínseca $(24 \%)$, caseum obstrutivo $(22 \%)$, tecido de granulação $(9 \%)$ e erosão da mucosa com ulceração $(3 \%){ }^{2}$

A TBEB é difícil diagnosticar porque, além da sintomatologia inespecífica, a lesão nem sempre é evidente na radiografia de tórax, retardando o diagnóstico e o tratamento. Dessa forma, além da suspeita clínica, o diagnóstico deve ser apoiado por exames de imagem, broncoscópico, microbiológico e histopatológico. ${ }^{4}$

A broncoscopia é um procedimento que pode ser diagnóstico e terapêutico. Ela pode identificar o comprometimento da mucosa brônquica nos casos de TBEB, permite o diagnóstico microbiológico e contribui na adequação do tratamento como nos casos de maior gravidade, em que há necessidade de ressecção para desobstrução da via aérea devido à presença de tecido de granulação ou massa polipoide. Assim, é considerado um método que pode contribuir: 1- confirmando a suspeita diagnóstica de TBEB, especialmente na criança pequena; e 2- na terapêutica, em que, diante de formas graves, pode-se associar o corticosteroide ao esquema antituberculose, na tentativa de evitar evolução com estenose traqueobrônquica. Pode contribuir também na avaliação do prognóstico da TBEB. ${ }^{3,8,10}$ Nesse procedimento, além da avaliação endoscópica das vias aéreas, pode-se obter amostras de secreção brônquica ou de LBA para estudo microbiológico (exame direto e cultura), material de biópsia brônquica ou transbrônquica, escovado para estudo citológico e, mais recentemente, com a ultrassonografia endobrônquica (EBUS) pode-se realizar aspiração por agulha do gânglio acometido, aumentando a rentabilidade do procedimento. ${ }^{3,12}$

Na doença ativa, os dois objetivos do tratamento são 
a erradicação dos bacilos, com início das drogas antituberculose, e a prevenção da estenose traqueobrônquica, com associação de corticosteroide. ${ }^{4,6,11}$ São poucas as informações sobre o uso de corticosteroide na TB primária da criança. Apesar de controverso, alguns autores o consideram vantajoso, especialmente nos casos mais graves e quando durante o tratamento o paciente apresenta reação de hipersensibilidade. , $^{4,13}$

Chan e cols. ${ }^{10}$ acompanharam a evolução da TBEB em adultos e observaram que a minoria dos pacientes que apresentaram reação de hipersensibilidade secundária ao início do tratamento específico evoluía com melhora dramática ao associar corticosteroide. Entretanto, naqueles que evoluíram com estenose por fibrose houve pouca interferência na evolução com o uso do corticosteroide.

Toppet e cols., ${ }^{14}$ em estudo duplo-cego incluindo 29 crianças portadoras de TB pulmonar primária e obstrução brônquica devido a linfonodomegalia hilar, observaram que o grupo que utilizou corticosteroide associado a drogas antituberculose obteve melhora mais rápida e significativamente apresentou menos complicações radiológicas e na broncoscopia. No esquema terapêutico de nosso paciente optou-se associar corticosteroide ao esquema tríplice devido à gravidade do envolvimento brônquico com a compressão extrínseca determinada por gânglio mediastinal com fistulização e drenagem de caseum.

A evolução da TBEB varia desde a resolução completa até o desenvolvimento de estenose traqueobrônquica residual, mais raramente descrito na criança. Porém, em alguns casos, mesmo com tratamento oportuno, pode haver progressão para estenose traqueobrônquica resultando frequentemente em sequelas na vida adulta como bronquiectasias. ${ }^{4,13}$ Dessa forma, é muito importante atentar para o diagnóstico de TBEB na criança e, neste caso, manter o acompanhamento regular visando à evolução para cura ou com complicações descritas acima.

Torna-se fundamental o papel do pediatra na suspeição da TB e no encaminhamento inicial para o diagnóstico e tratamento precoce, atentando sempre para o sistema de pontuação do MS. Porém, deve-se ter ciência da possibilidade de TBEB nos casos de TB pulmonar com alteração radiológica sugestiva de envolvimento da árvore traqueobrônquica, tais como hiperinsuflação e atelectasia. A necessidade de broncoscopia deverá ser avaliada nas crianças com suspeita de TB pulmonar grave, com evolução incomum, mantendo indícios radiológicos de compressão e/ou envolvimento traqueobrônquico, apesar do tratamento específico adequado, sugerindo TBEB.

\section{REFERÊNCIAS}

1 Ministério da Saúde. Secretaria de Vigilância em Saúde. Departamento de Vigilância Epidemiológica. Manual de recomendações para o controle da tuberculose no Brasil [acesso em 11 fev 2019]. Brasília: MS; 2011. Disponível em: http:// bvsms.saude.gov.br/bvs/publicacoes/manual_recomendacoes_ controle_tuberculose_brasil.pdf

2 Cakir E, Kut A, Ozkaya E, Gedik AH, Midyat L, Nursoy $M$. Bronchoscopic evaluation in childhood pulmonary tuberculosis: risk factors of airway involvement and contribution to the bacteriologic diagnosis. Pediatr Infect Dis J. 2013;32(8):921-3. DOI: https://doi.org/10.1097/ INF.0b013e31829042a0

3 Goussard P, Gie R. The role of bronchoscopy in the diagnosis and management of pediatric pulmonary tuberculosis. Expert Rev Respir Med. 2014;8(1):101-9. DOI: https://doi.org/10.1586 /17476348.2013.863712

4 Siow WT, Lee P. Tracheobronchial tuberculosis: a clinical review. J Thorac Dis 2017;9(1):E71-E77. DOI: http://dx.doi org/10.21037/jtd.2017.01.49

5 Thampi N, Stephens D, Rea E, Kitai I. Unexplained deterioration during antituberculous therapy in children and adolescents: clinical presentation and risk factors. Pediatr Infect Dis J. 2012;31(2):129-33. DOI: https://doi.org/10.1097/ INF.0b013e318239134c

6 Lucas S, Andronikou S, Goussard P, Gie R. CT features of lymphobronchial tuberculosis in children, including complications and associated abnormalities. Pediatr Radiol. 2012;42(8):923-31. DOI: https://doi.org/10.1007/ s00247-012-2399-x

7 Wong JSW, Ng CSH, Lee TW, Yim APC. Bronchoscopic management of airway obstruction in pediatric endobronchial tuberculosis. Can Respir J. 2006;13(4):219-21. DOI: https:// doi.org/10.1155/2006/278680

8 Jiao AX, Sun L, Liu F, Rao XC, Ma YY, Liu XC et al. Characteristics and clinical role of bronchoscopy in diagnosis of childhood endobronchial tuberculosis. World J Pediatr. 2017;13(6):599-603. DOI: https://doi.org/10.1007/ s12519-017-0046-1

9 Arreo Del Val V, Díaz Marugán V, Alcobendas R. Tuberculosis endobronquial como causa de neumonía refractaria. An Pediatr (Barc). 2011;75(3):217-9. DOI: https://doi. org/10.1016/j.anpedi.2010.11.008

10 de Blic J, Azevedo I, Burren CP, Le Bourgeois M, Lallemand $\mathrm{D}$, Scheinmann $\mathrm{P}$. The value of flexible bronchoscopy in childhood pulmonary tuberculosis [access on Feb 11, 2019]. Chest. 1991;100(3):688-92. Available from: https://journal. chestnet.org/article/S0012-3692(16)32794-5/fulltext

11 Chan HS, Sun A, Hoheisel GB. Endobronchial tuberculosis: is corticosteroid treatment useful? A report of 8 cases and review of the literature [access on Feb 11, 2019]. Postgrad Med J. 1990;66(780):822-6. Available from: http://pmj.bmj.com/cgi/ pmidlookup? view $=$ long $\&$ pmid $=2099420$

12 Tagarro García A, Barrio Gómez de Agüero MI, Martínez Carrasco C, Antelo Landeira C, Díez Dorado R, del Castillo F et al. Fiberoptic bronchoscopy in childhood endobronchial tuberculosis. An Pediatr (Barc). 2004;61(4):314-9.

13 Kiral N, Caglayan B, Salepci B, Torun Parmaksiz E, Fidan A, Comert SS et al. Endobronchial ultrasound-guided 
transbronchial needle aspiration in diagnosing intrathoracic tuberculous lymphadenitis. Med Ultrason. 2015;17(3):333-8. DOI: https://doi.org/10.11152/mu.2013.2066.173.nki

14 Toppet M, Malfroot A, Derde MP, Toppet V, Spehl M, Dab
I. Corticosteroids in primary tuberculosis with bronchial obstruction [access on Feb 11, 2019]. Arch Dis Child. 1990;65(11):1222-6. Available from: https://www.ncbi.nlm. nih.gov/pmc/articles/PMC1792610/ 